\title{
Effects of Digoxin on Diaphragmatic Contractility in the Piglet
}

\author{
DENNIS E. MAYOCK, THOMAS A. STANDAERT, AND DAVID E. WOODRUM \\ Department of Pediatrics, Division of Neonatal and Respiratory Diseases, University of Washington School of \\ Medicine, Seattle, Washington 98195
}

\begin{abstract}
Minute ventilation, arterial blood gases and pH, cardiac output, and transdiaphragmatic force generation were measured in eight anesthetized, tracheostomized piglets before and after administration of $40 \mu \mathrm{g} / \mathrm{kg}$ body wt of digoxin. No changes were noted in cardiac output, heart rate, tidal vol, respiratory rate, or minute ventilation. Blood pressure decreased from baseline to $60 \mathrm{~min}$ postinfusion. No change was noted in the force frequency curves at 30 and $60 \mathrm{~min}$ postinfusion. Serum digoxin levels averaged $10.4 \mathrm{ng} / \mathrm{mL}$ at $30 \mathrm{~min}$ and $5.6 \mathrm{ng} / \mathrm{mL}$ at $60 \mathrm{~min}$. In seven control animals, no changes were noted in any ventilatory or hemodynamic parameter from baseline to 60 min. In contrast to the reported effects of digoxin on the diaphragm of adult humans and animals, digoxin did not augment diaphragmatic contractility in normal infant swine. (Pediatr Res 25:271-273, 1989
\end{abstract}

\section{Abbreviations}

Pdi, transdiaphragmatic pressure Paw, airway pressure

The cardiac glycosides are thought to facilitate cardiac muscle fiber contractility by augmentation of calcium flux from the extracellular space into the sarcoplasm $(1,2)$. This effect was considered to be exclusive for the myocardium (3). However, recent studies suggest that diaphragmatic muscle may also respond to digoxin. In an unfatigued in vivo dog model, Aubier et al. (4) demonstrated a significant positive inotropic effect of digoxin on diaphragmatic force generation without altering cardiac output or diaphragmatic blood flow. No effect of digoxin was noted on the sartorius muscle of these same animals. Aubier et al. (5) also found similar improvement in diaphragmatic force generation in adult human subjects suffering from chronic obstructive pulmonary disease complicated by acute respiratory failure. These studies point out the similarities between myocardial and diaphragmatic muscle tissue and open up new avenues for possible therapeutic intervention.

No information on the effects of the cardiac glycosides on developing respiratory muscle is available. Accordingly, this study examined the effects of the cardiac glycoside, digoxin, on the force-generating capabilities of the nonfatigued piglet diaphragm. Additionally, the effect of digoxin on hemodynamic parameters was assessed. It was hypothesized that digoxin would enhance diaphragmatic force generation in the young piglet as previously found in adult human and animal investigations.

Received August 1, 1988; accepted October 31, 1988

Correspondence Dennis E. Mayock, M.D., Division of Neonatal and Respiratory Diseases, Department of Pediatrics, University of Washington, Seattle, WA 98195

Supported in part by Pediatric Pulmonary Training Grants MCJ 000955 and HL 39187.

\section{MATERIALS AND METHODS}

Young piglets at 4-5 wk postnatal age were obtained from the University of Washington Division of Animal Medicine Vivarium. Study animals were required to be healthy with a respiratory rate of 15-30 breaths/min, a $\mathrm{Pa}_{\mathrm{O}_{2}}$ of more than 60 torr in room air, and a $\mathrm{Pa}_{\mathrm{CO}_{2}}$ equal to or less than 50 torr. The animals were instrumented under chloralose/urethane anesthesia. Subsequent infusions of anesthetic were used if the piglet developed jaw clonus. A tracheostomy tube was placed and connected to a Hans-Rudolph 2-way nonrebreathing valve. Expiratory flow was detected by a hot wire anemometer and integrated to provide tidal vol. A femoral artery catheter was placed to measure heart rate and blood pressure, and for blood gas and $\mathrm{pH}$ sampling. Rectal temperature was continuously monitored and maintained at $38.5-39.5^{\circ} \mathrm{C}$ by a radiant warmer (6).

Force frequency curves were generated by the transvenous phrenic nerve stimulation technique previously described $(7,8)$. The phrenic nerves were stimulated via bilateral indwelling external jugular vein catheter electrodes at supramaximal voltage at $20,30,50$, and $100 \mathrm{~Hz}$. A thin-walled latex balloon containing $0.5 \mathrm{~mL}$ of air was connected to a polyethylene catheter $(1.65$ $\mathrm{mm}$ inner diameter) and placed in the stomach to measure gastric pressure. Paw was measured by a P10EZ (Spectramed, Inc., Oxnard, CA) pressure transducer connected to a 18-gauge needle inserted in the tracheostomy tube proximal to the nonrebreathing valve. Recent work in our laboratory has investigated the relationship between Paw, esophageal pressure, and intrapleural pressure in six comparably aged piglets. The ratio of Peso to $\mathrm{Ppl}$ (esophageal pressure to intrapleural pressure) during airway occlusion at end expiration was found to be $0.86 \pm 0.04$ during spontaneous breathing and $0.67 \pm 0.24$ during phrenic nerve stimulation at $100 \mathrm{~Hz}$. In contrast, Paw/intrapleural pressure averaged $0.96 \pm 0.04$ during spontaneous breathing and $0.96 \pm 0.06$ during nerve stimulation. Therefore, Pdi was measured as gastric pressure (Pga) - Paw.

A preformed plaster cast covering the entire abdomen and lower third of the chest was applied during force frequency curve generation to ensure a constant degree of diaphragmatic shortening. The piglets were allowed to breathe unrestrictedly between stimuli. A Swan-Ganz thermodilution cardiac output catheter (No. 5 French with $10-\mathrm{cm}$ proximal port) was placed into the pulmonary artery under fluoroscopic guidance. Measures of cardiac output were obtained in triplicate using $2 \mathrm{~mL}$ iced $5 \%$ dextrose in water. Functional residual capacity was measured by the nitrogen washout technique (9) in three of these animals to assess the effect of the protocol on lung vol and, thus, diaphragmatic length.

Experimental protocol. Two groups of animals were studied (control and experimental) after a 30-min stabilization period. Baseline data for both groups included arterial blood gases and $\mathrm{pH}$, ventilatory parameters (tidal vol, frequency, minute ventilation) cardiac output, systemic blood pressure, heart rate, and force frequency curve.

There were seven animals in the control group. Data were collected during baseline and again at $60 \mathrm{~min}$. No digoxin was 
administered to control animals. There were eight animals in the experimental group. They received a digoxin infusion $(0.40 \mathrm{mg} /$ $\mathrm{kg}$ ) over $10 \mathrm{~min}$ after baseline data collection. Data were again collected at 30 and 60 min postinfusion. Serum digoxin levels were obtained at 30 and 60 min postdigoxin infusion.

To allow for possible changes in stability of the preparation with time, the percentage of change in transdiaphragmatic force generation at each frequency was compared between the control and the digoxin-treated animals. The percentage of change from baseline for transdiaphragmatic force generation was compared with the $t$ test for unpaired data. Within group data were compared using the $t$ test for paired results corrected for repeated measures.

\section{RESULTS}

Control animals. The seven control piglets were studied at a mean postnatal age of $31 \mathrm{~d}$ (range 28-32 d). Mean body wt was $4.22 \pm 0.19 \mathrm{~kg}$. No changes in arterial blood gases and $\mathrm{pH}$ were noted between baseline and $1 \mathrm{~h}$. Hemodynamic data during the baseline period and repeated in $1 \mathrm{~h}$ are presented in Table 1 . No significant changes were noted during the 1-h study period. Similarly, no differences were noted in any ventilatory measurement between baseline and $60 \mathrm{~min}$ (Table 2). Transdiaphragmatic force generation was not different at 60 min when compared with baseline (Figure 1).

Experimental animals. The eight piglets that received digoxin infusion were studied at a mean postnatal age of $30 \mathrm{~d}$ (range 29$32 \mathrm{~d}$ ). Body wt at the time of study was $5.30 \pm 1.57 \mathrm{~kg}$. Digoxin had no significant effect on cardiac output or heart rate (Table 1). Mean blood pressure decreased from baseline to $60 \mathrm{~min}$ after digoxin $(p=0.028)$. No significant changes in ventilatory measurements from baseline were noted at 30 or $60 \mathrm{~min}$ postdigoxin infusion (Table 2). No changes were noted in blood gases or $\mathrm{pH}$. Pdi during baseline and at 30 and 60 min postdigoxin infusion is illustrated in Figure 2. Although the mean force generated at each frequency decreased at 30 and $60 \mathrm{~min}$ postdigoxin, no significant change was found when compared to changes in the control group. Functional residual capacity did not change from baseline to 60 min postdigoxin infusion $(n=3,21 \pm 1.8 \mathrm{~mL} / \mathrm{kg}$ versus $20.9 \pm 0.8 \mathrm{~mL} / \mathrm{kg}$ ). Digoxin serum levels after digoxin administration averaged $10.4 \pm 3.3 \mathrm{ng} / \mathrm{mL}$ at $30 \mathrm{~min}(n=7)$ and $5.6 \pm 2.2 \mathrm{ng} / \mathrm{mL}$ at $60 \mathrm{~min}(n=8)$.

\section{DISCUSSION}

Digoxin administration did not lead to an augmentation in diaphragmatic force generation in the nonfatigued piglet. Thus, the hypothesis of this study was rejected. No changes were noted in any ventilatory parameter or in functional residual capacity. Blood pressure decreased from baseline significantly at $60 \mathrm{~min}$ after digoxin infusion. Heart rate and cardiac output were unchanged throughout the study. No changes were noted in any parameter of the control animal group.

Table 1. Hemodynamic parameters*

\begin{tabular}{|c|c|c|c|}
\hline & $\begin{array}{l}\text { Cardiac output } \\
(\mathrm{mL} / \mathrm{kg} / \mathrm{min})\end{array}$ & $\begin{array}{l}\text { Heart rate } \\
\text { (beats/min) }\end{array}$ & $\begin{array}{c}\text { Systemic blood } \\
\text { pressure (mm } \\
\mathrm{Hg}) \\
\end{array}$ \\
\hline \multicolumn{4}{|l|}{ Baseline } \\
\hline Control animals & $255 \pm 50$ & $160 \pm 32$ & $98 \pm 7$ \\
\hline Experimental animals & $216 \pm 66$ & $157 \pm 39$ & $110 \pm 13$ \\
\hline \multicolumn{4}{|l|}{$30 \mathrm{~min}$} \\
\hline Experimental animals & $210 \pm 70$ & $156 \pm 43$ & $94 \pm 12$ \\
\hline \multicolumn{4}{|l|}{$60 \mathrm{~min}$} \\
\hline Control animals & $248 \pm 40$ & $164 \pm 35$ & $100 \pm 6$ \\
\hline Experimental animals & $210 \pm 60$ & $173 \pm 34$ & $91 \pm 13 \dagger$ \\
\hline
\end{tabular}

* All values are mean $\pm \mathrm{SD}$

$\dagger p<0.05$ compared to baseline.
Table 2. Ventilatory parameters*

Tidal volume Respiratory rate Min ventilation

$(\mathrm{mL} / \mathrm{kg}) \quad$ (breaths $/ \mathrm{min}) \quad(\mathrm{mL} / \mathrm{kg} / \mathrm{min})$

\begin{tabular}{llll}
\hline Baseline & & & \\
$\quad$ Control animals & $11.4 \pm 1.2$ & $16.9 \pm 4.9$ & $169.1 \pm 47.5$ \\
$\quad$ Experimental animals & $11.0 \pm 4.5$ & $18.1 \pm 7.9$ & $185.9 \pm 72.1$ \\
30 min & & & \\
$\quad$ Experimental animals & $12.6 \pm 3.8$ & $16.5 \pm 8.9$ & $194.0 \pm 79.1$ \\
60 min & & & \\
$\quad$ Control animals & $11.2 \pm 2.0$ & $16.2 \pm 3.5$ & $165.2 \pm 46.8$ \\
$\quad$ Experimental animals & $12.8 \pm 3.9$ & $14.6 \pm 4.4$ & $177.1 \pm 44.4$ \\
\hline
\end{tabular}

* All values are mean $\pm \mathrm{SD}$. No significant changes in any parameter were noted from baseline values.

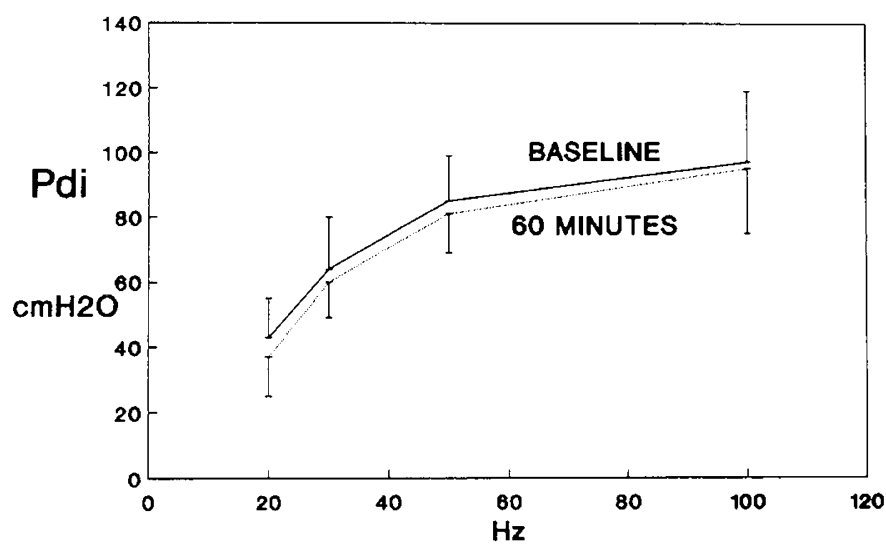

Fig. 1. Control animals. No change in the force frequency curve was noted from baseline (solid line) to $60 \mathrm{~min}$ (dotted line). Mean \pm SEM.

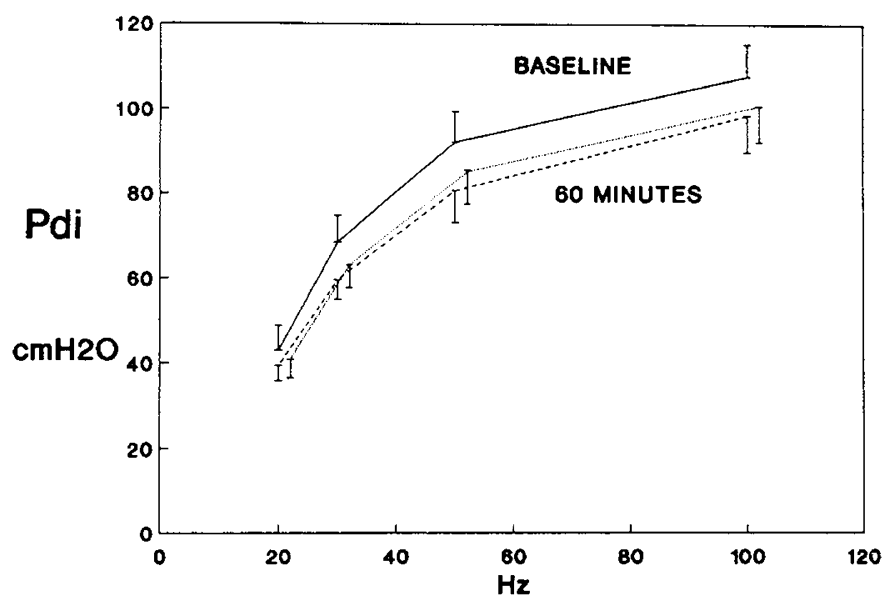

Fig. 2. Experimental animals. Force frequency curves generated during baseline (solid line), at $30 \mathrm{~min}$ (dotted line, not labeled for clarity), and at $60 \mathrm{~min}$ (broken line) postdigoxin infusion. Mean \pm SEM. The 30 min error bars are offset for clarity.

These data from digoxin-treated young animals are different from those previously reported in studies of adult humans and animals. Aubier et al. (4) found a dose-dependent augmentation of transdiaphragmatic force generation after digoxin administration in unfatigued, mechanically ventilated adult dogs. Digoxin had no effect on force generation of peripheral skeletal muscle in the same animals. Kikuchi et al. (10) studied the effect of cardiac glycosides on the contractility on both the fatigued and nonfatigued diaphragm in ventilated dogs. Ouabain increased transdiaphragmatic force generation in a dose-dependent manner. Deslanoside was found to have a variable effect, failing to increase force generation in the nonfatigued muscle, but provid- 
ing some protection against fatigue when used in a pretreatment protocol. These data generally supported those of Aubier et al. in that they suggest a positive effect of cardiac glycosides on force generation of the adult diaphragm. Finally, it is notable that in a recent study (5), adult humans with respiratory failure secondary to chronic obstructive pulmonary disease were found to respond to an infusion of digoxin by significantly increasing their transdiaphragmatic peak twitch tension. These data all point to the conclusion that the adult diaphragm increases force output in response to cardiac glycoside administration. Indeed, the studies cited above were based on evidence that suggests that the diaphragm, formerly categorized more as a striated or skeletal type muscle, demonstrates characteristics that are more similar to cardiac muscle $(11,12)$. Specifically, the entry of extracellular calcium into the cell may be an important component of the contractile cycle of the diaphragm muscle fiber.

\section{CRITIQUE}

The inability to document force augmentation after digoxin infusion in this study requires a critical reevaluation of the model used. Factors such as acidosis, hypoxia, temperature instability, and hypercarbia could compromise the stability of the model and result in an interference with optimal diaphragmatic contractility. However, neither the control nor the experimental animals demonstrated any alterations in ventilatory parameters, arterial blood gases, or acid-base balance. Temperature was maintained at $39.5 \pm 0.5^{\circ} \mathrm{C}$ by external means as necessary. A small, but significant decrease in mean arterial blood pressure was found at $60 \mathrm{~min}$ in the digoxin treated animals. However, this blood pressure value was still within a normally acceptable range for the size and age of animal involved (6-8). Therefore, the lack of force augmentation after administration was not secondary to deterioration in the preparation itself. A second consideration to explain our results would be that the force frequency curves were in error or generated improperly. Electrode placement requires careful positioning of the tips to result in symmetric diaphragm contraction. It has been our experience with this technique that placement should not result in activation of muscles supplied by branches of the brachial plexus such as the forelimbs nor result in cardiac arrhythmias (6-8). Once maximal symmetric diaphragmatic contraction has been elicited and the electrodes are placed just beyond the point of brachial plexus activation, they are secured in place with ligatures around the vessels, and no further alteration of position is attempted. This procedure has resulted in stable force frequency curve generation for up to $6 \mathrm{~h}$ (14; Mayock DE, unpublished data).

Additionally, alterations in lung vol or chest wall configuration could jeopardize our ability to demonstrate force augmentation after digoxin administration. A preformed plaster cast was applied during phrenic nerve stimulation to limit the degree of diaphragm shortening. Moreover, functional residual capacity was measured to assess lung vol before and after digoxin. If lung vol increased, the force-generating capability of the diaphragm would be compromised as the diaphragm would be shorter and on a less optimal portion of its length-tension curve (14). Conversely, a decrease in lung vol would have the opposite effect. The stability of the functional residual capacity after digoxin administration, and the use of the cast suggests that the decrease in force generation is not secondary to alterations in lung vol change.

Figure 2 suggests that force generation attenuation occurred after digoxin infusion. The percentage of change from baseline to 30 and $60 \mathrm{~min}$ postdigoxin infusion was not, however, statistically different from control animals. Digoxin toxicity is a possible explanation for the lack of force augmentation found in this study. Digoxin is a well-recognized toxin and may have exerted such an effect in this animal preparation after its administration. Though the dose of digoxin administered is similar to that used in term human infants for digitilization (15), the levels of digoxin found at 30 and 60 min postinfusion are in the toxic range for both adult and newborn humans. Force attenuation was reported in the in vitro guinea pig diaphragm when it was exposed to high concentrations of ouabain (16). The mechanism of this negative inotropic effect was not delineated in that study (16), but may result from hypopolarization of the cell membrane secondary to impaired potassium reuptake $(17,18)$. Interestingly, the pattern of force generation fall-off was similar to that noted for high-frequency fatigue (19).

Cardiac glycosides alter excitation-contraction coupling by increasing intracellular calcium ion concentration, thereby resulting in enchanced force generation $(1,20)$. Part of this effect results from augmentation of calcium induced-calcium release from the sarcoplasmic reticulum $(20,21)$. Sarcoplasmic reticulum development in neonatal respiratory muscle is incomplete (22). The lack of force augmentation found in the present study may be the result of this immature stage of development. It may be that the respiratory muscles of the young piglet are already functioning at their optimal ability and contraction efficiency cannot be augmented pharmacologically.

\section{REFERENCES}

1. Katz AM, Repke DI 1973 Calcium-membrane interactions in the myocardium effects of ouabain, epinephrine and $3^{\prime}, 5^{\prime}$-cyclic adenosine monophosphate. Am J Cardiol 31:193-201

2. Smith TW 1988 Digitalis: mechanisms of action and clinical use. N Engl J Med 318:358-365

3. Moran N 1972 The effects of cardiac glycosides on mechanical properties of heart muscle. In: Marks BM, Weissler AM (eds) Basic and Clinical Pharmacology of Digitalis. Charles C Thomas, Springfield, IL, pp 94-117

4. Aubier M, Viires N, Murciano D, Seta J-P, Pariente R 1986 Effects of digoxin on diaphragmatic strength generation. J Appl Physiol 61:1767-1774

5. Aubier M, Murciano D, Viires N, Lebargy F, Curran Y, Seta J-P, Pariente R 1987 Effects of digoxin of diaphragmatic strength generation in patients with chronic obstructive pulmonary disease during acute respiratory failure. Am Rev Respir Dis 135:544-548

6. Mount LE, Ingram DL 1971 Physiology. In: The Pig as Laboratory Animal. Academic Press, New York, pp 65-78

7. Watchko JF, Mayock DE, Standaert TA, Woodrum DE 1986 Diaphragmatic pressures in piglets: transvenous versus direct phrenic nerve stimulation. Pediatr Pulmonol 2:198-201

8. Mayock DE, Badura RJ, Watchko JF, Standaert TA, Woodrum DE 1987 Response to resistive loading in the newborn piglet. Pediatr Res 21:121-125

9. Standaert TA, LaFramboise WA, Tuck RE, Woodrum DE 1985 The serial determination of lung volume in small animals by nitrogen washout. J Appl Physiol 59:205-210

10. Kikuchi Y, Hida W. Shindoh C, Chonan $\Upsilon$, Miki H, Sakurai M, Inoue $H$ Takishima T 1987 Effect of digitalis on the diaphragm in anesthetized dogs. J Appl Physiol 63:277-284

11. Aubier M, Viires N, Piquet J, Murciano D, Blanchet F, Marty C, Gherardi R Pariente R 1985 Effects of hypocalcemia on diaphragmatic strength generation. J Appl Physiol 58:2054-2061

12. Aubier M, Murciano D, Viires N, Lecocguic Y, Pariente R 1983 Diaphragmatic contractility enchanced by aminophylline: role of extracellular calcium. J Appl Physiol 54:460-464

13. Watchko JF, Standaert TA, Mayock DE, Twiggs G, Woodrum DE 1988 Ventilatory failure during loaded breathing: the role of central neural drive. J Appl Physiol 65:249-255

14. Watchko JF, Standaert TA, Woodrum DE 1987 Diaphragmatic function during hypercapnia: neonatal and developmental aspects. J Appl Physiol 62:768-775

15. Park MK 1986 Use of digoxin in infants and children, with specific emphasis on dosage. J Pediatr 108:871-877

16. Faust RM, Saunders PR 1957 Comparative effects of ouabain upon contractile force of guinea pig diaphragm and heart. Proc Soc Exp Biol Med 94:351356

17. Sherman M, Aldrich T, Chaudhry I, Nagashima H 1988 The effect of digoxin on contractility and fatigue of isolated guinea pig diaphragms. Am Rev Respir Dis 137:70(abstr)

18. Esau SA 1988 Theophylline prevents the depolarization of skeletal muscle membrane by hypoxic, hypercapnic acidosis. Am Rev Respir Dis 137:385(abstr)

19. Edwards RHT, Hill DR, Jones DA, Merton PA 1977 Fatigue of long duration in human skeletal muscle after exercise. J Physiol (Lond) 272:769-778

20. Smith TW, Haber E 1973 Digitalis. N Engl J Med 289:945-952

21. Adams RJ, Schwartz A 1980 Comparative mechanisms for contraction of cardiac and skeletal muscle. Chest 78:123-139(suppl)

22. Maxwell LC, McCarter RJM, Kuehl TJ, Robotham JL 1983 Development of histochemical and functional properties of baboon respiratory muscles. J Appl Physiol 54:551-561 